\title{
Living With Robots: A Speculative Design Approach
}

\author{
James Auger \\ Design Interactions \\ Royal College of Art
}

This article begins by asking: "Why are robots not becoming domestic products?" In addressing this question the author borrows from the science of ecology and biological concepts of evolution and domestication to make an analogy between the shift of habitats that occurs when an organism successfully goes through the process of artificial selection (from natural to domestic). In addition, this paper explores the transition an emerging technology makes when coming out of the laboratory and becoming a suitable product for domestic use, concluding that the majority of proposed domestic robots are essentially maladapted to everyday life.

The article then shifts the focus onto design research, primarily speculative design, to ask, "how could robots become domestic products?" The author uses a variety of design projects to describe how alternative approaches to robots can provide new perspectives on technological research and development.

Keywords: human-robot interaction, recognition, sensors, emotion

\section{Introduction}

Robots are thriving in research laboratories and technology fairs, in the novels and films of science fiction, on production lines, and in other industrial situations. In these habitats, their raison d'etre is justified by meeting the functional and aesthetic requirements defined by these specific contexts. The expectation is that versions of these robots will soon move into our homes and other everyday-life situations. The potential of this transition has inspired many of the future imaginaries that have existed for almost a century, however, aside from the occasional robotic vacuum cleaner, lawn mower, or replica pet, it is a shift that has yet to happen. If robots are to succeed in securing a place in our homes, then they will effectively have to change ecosystems, migrating from the habitat in which they currently reside to that of everyday life. One way of describing this specific journey between systems is domestication: "Selection carried out by man for the purpose of adapting plants and animals to his needs" (Odum, 1971, p. 242).

I will begin by examining the complex requirements of the domestic habitat with the aim of explaining the lack of progress made in adapting robots to it. I will then introduce a design approach to the subject-primarily speculative design to first explain some of the methods and motivations and then suggest how it can offer valuable insights into how emerging robotic technologies could be domesticated.

\footnotetext{
Authors retain copyright and grant the Journal of Human-Robot Interaction right of first publication with the work simultaneously licensed under a Creative Commons Attribution License that allows others to share the work with an acknowledgement of the work's authorship and initial publication in this journal.
} 


\section{On Design}

As a design special on human-robot interaction, it is perhaps helpful to say a few things about design to clear any misunderstandings or confusion, especially when a non-familiar audience is confronted with conceptual proposals. The renowned 20th century designer Charles Eames (1972) described design as "a plan for arranging elements to accomplish a particular purpose." The beauty of this simple statement is that it operates across multiple scales, material complexities and time frames - from a piece of furniture to a city's plan; a length of wood to biological parts (now seen as being designable through synthetic biology); and for the real marketplace of tomorrow or a conceptual future world. Most helpful for this discussion is the notion of a particular purpose; a relatively straightforward function or value when the subject is a chair (more comfortable, aesthetically pleasing, or a financial gain) but potentially difficult to ascertain when viewing a speculative or critical design proposal — what is the point of non-market orientated speculative proposals?

The simple answer to this issue of purpose is that speculative design is predominantly about asking questions - it provides a philosophical enquiry into technological application that strives to facilitate a more considered and democratic approach through curated discussion and debate. By operating outside of normative design contexts, this enquiry is free from the demands of industry and the market forces that inform the majority of technological trajectories. This freedom facilitates a shift away from familiar notions, established lineages and contextual expectations to reimagine things and worlds inspired by different ideologies or motivations.

Applying this approach to HCI is hopefully illuminating-from the critical aspect of employing notions of domestication and adaptation to understand why robots are not becoming products and how speculative design can be used to examine and expose these reasons and observations. It is important to emphasise that speculative design does not claim to provide answers to the questions it asks - none of the design projects described below have the goal of becoming actual domestic products. This is perhaps where it becomes exposed to the strongest criticism. My response to this is that the methodology is not based on short-term solutions but has the purpose of providing a longer-term, more critical approach to technological research and development. By asking the right questions of a broad audience, the research has the potential to inform and redirect technological trajectories by exposing them much sooner to the complex rules of everyday life.

\section{Domestication and Domestication Theory}

First, it is important to note that the idea of domesticating technology is not original-in media and communication studies, for example, it has been described as follows:

Domestication, in the traditional sense, refers to the taming of a wild animal. At a metaphorical level, we can observe a domestication process when users, in a variety of environments, are confronted with new technologies. These 'strange' and 'wild' technologies have to be 'house-trained'; they have to be integrated into the structures, daily routines and values of users and their environments. (Berker et al., 2006, p. 2)

Through the use of the term 'house-trained', Berker's analogy infers the specific time frame between the introduction of an animal (such as a dog) into the home, and its complete integration into the rules, systems, and behaviours laid down by its new owner. Fundamentally, this description ignores the genetic journey made by that dog's ancestors over the past 12,000-15,000 years - the journey that allowed for the dog to be an appropriate candidate for cohabitation with humans. It is possible to resolve this issue by 
introducing a distinction between technology and product-domestication studies, as described above, therefore relate to the domestication of the product, and what is discussed here relates to the domestication of technology-effectively, the creation of a consumable product from technological potential.

This approach means that a domesticated robot could be seen as a product rather than as an object of research or science fiction, thereby introducing the rules and expectations of the domestic habitat and the role of design in adapting technology to it. It is primarily through (industrial) design that technological potential is transformed into attractive and easy-to-use products. In this process, the designer considers not only obvious elements such as form, function, interaction, ergonomics, and materials but also more complex human issues such as the desires and idiosyncrasies of the intended audience and the fluctuations of fashion and trends.

By understanding the complex rules and conditions of domestic life, it becomes possible to make sense of the obvious disparity between the promise of the spectacular robot as imagined by film directors, writers, scientists, and corporations, and what is actually available to the public today.

\section{The complexity of the domestic object—utility and post utility}

Ethnographic explorations into people and their relationship with the home, such as Daniel Miller's The Comfort of Things; The Meaning of Things-Domestic Symbols and the Self by Csikszentmihalyi and Rochberg-Halton, and Jean Baudrillard's The System of Objects are insightful in describing some of the means and methods through which objects become incorporated into our everyday lives. They also expose the complexity of the domestic object:

There are almost as many criteria of classification as there are objects themselves: the size of the object; its degree of functionality (i.e., the object's relationship to its own objective function); the gestures associated with it (are they rich or impoverished? Traditional or not?); its form; its duration; the time of day at which it appears (more or less intermittent presence, and how conscious one is of it); the material that it transforms (obvious in the case of a coffee grinder, less so in the case of a mirror, a radio, or a car - though every object transforms something); the degree of exclusiveness or sociability attendant upon its use (is it for private, family, public, or general use?); and so on. (Baudrillard, p. 1)

Baudrillard goes on to make a poignant division when classifying domestic products. This stems from his rather specific use of the word objet: "anything which is the cause or subject of a passion; figuratively-and par excellence-the loved object." $(2005, \text { p. } 91)^{1}$. He describes the two functions of any object: "to be put to use and to be possessed ... these two functions stand in inverse ratio to each other" (Baudrillard, 2005). This notion-that the emotional object must be divorced from any utilitarian aspect has also been noted by the ethnologist J. P. Digard in relation to pets:

The most misunderstood yet perhaps the most interesting aspect of pets is doubtlessly the following: to be permitted to become close friends with their owners, these animals have to be completely available for them and to have no other purpose than just being their owners' companion. (1990, p. 234)

Baudrillard, quoting Maurice Rheims, conveniently goes on to liken the object to a dog: "For man, the object is a sort of insentient dog which accepts his blandishments and returns them after his own fashion, or rather, which returns them like a mirror faithful not to real images but to images that are desired." (Rheims, La vie étrange des objets, p. 50, cited in Baudrillard, 2005, p. 95). This personalisation of the image neatly represents the complex emotional and psychological

\footnotetext{
${ }^{1}$ Here Baudrillard quotes from Littré's French Dictionary with the definition for objet (object).

2 For example, after the release of the 1985 version of the Disney movie '101 Dalmatians', new Dalmatian registrations increased 6.2-fold, from 6,880 registratiớls in 1985 to 42,816 registrations in 1993, followed by
} 
factors exhibited by the post-utility object: No longer are form and function defined by the satisfying of tangible and relatively stable human needs, but rather are governed by a much more complex and extremely ephemeral set of criteria. This is exemplified by the ebb and flow of dog breeds, in sync with cultural trends, Hollywood films, and celebrity behaviour ${ }^{2}$.
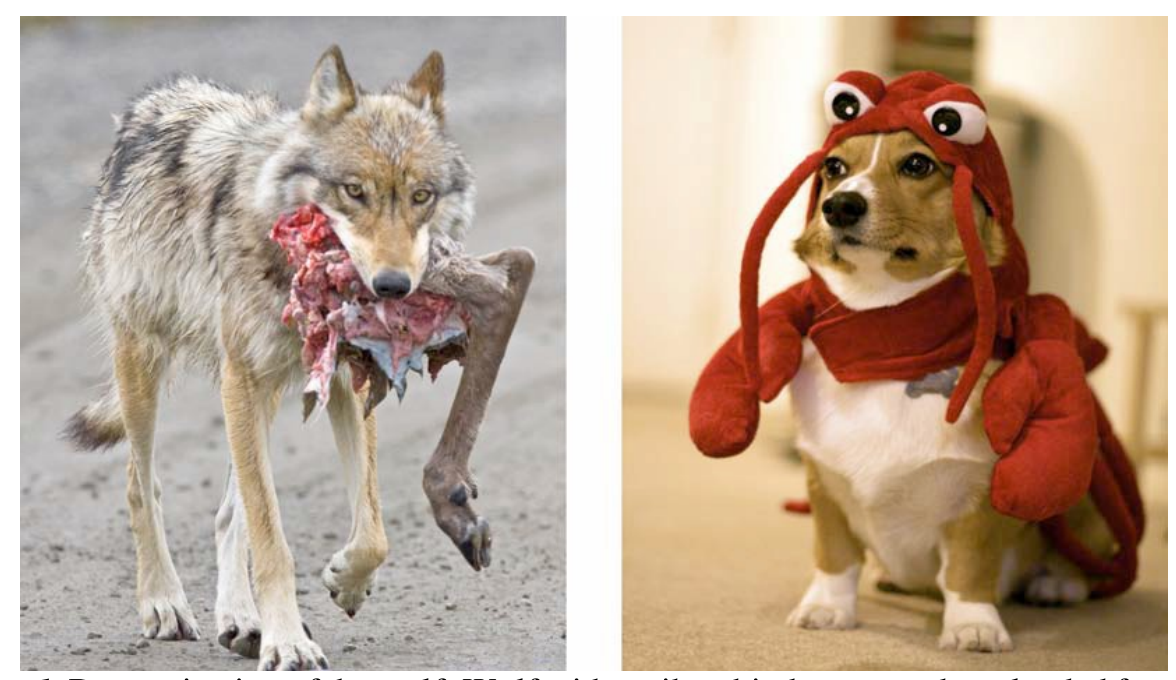

Figure 1. Domestication of the wolf. Wolf with caribou hindquarters, downloaded from: http://www.flickr.com/photos/denalinps/5300989487/

Red Lobster dog, downloaded from:

http://www.flickr.com/photos/deadvideokid/2969881139/

In his study of domestication, Michael Pollan explains why the dog has been so successful in securing a place in our homes and emotions:

The big thing the dog knows about- the subject it has mastered in the ten thousand years it has been evolving at our side - is us: our needs and desires, our emotions and values, all of which it has folded into its genes as part of a sophisticated strategy for survival. If you could read the genome of the dog like a book, you would learn a great deal of who we are and what makes us tick. (Pollan, 2002, p. XV)

Likewise, successful designers also have a mastery of $u s$. They move beyond generic notions of the user and simplistic notions of function to understand and embrace the genuine complexity and transience of human needs and desires and fundamentally how an object or organism can be designed or adapted to satisfy them.

\section{Maladaptation: Why robots are not becoming products}

Notions of domestication can be applied to technology by employing the theory of adaptation, described by the evolutionary biologist Theodosius Dobzhansky as "the evolutionary process

\footnotetext{
2 For example, after the release of the 1985 version of the Disney movie '101 Dalmatians', new Dalmatian registrations increased 6.2-fold, from 6,880 registrations in 1985 to 42,816 registrations in 1993, followed by a precipitous fall to 4,652 registrations six years later (Herzog, Bentley, and Hahn, 2004). In addition, the following statement was made on a Chihuahua enthusiasts website in 2004: "Following the release of the film 'Legally Blonde' three years ago and after several celebrities (including most famously X-Factor judge Sharon Osbourne) acquired Chihuahuas, they have become highly sought after pets. Many people have been searching for their ideal Chihuahua for over a year. Please remember that a Chihuahua is not a fashion accessory."
} 
whereby an organism becomes better able to live in its habitat" $(1968, \mathrm{p} .1)$. This definition is helpful because it describes the dynamic relationship between an organism and its environment.

By applying this concept to robots, a few key observations can be made: First, there is no goal or intention driving adaptation in nature. Technological development, however, is driven by extremely complex and diverse human motivations; while it is commonly inferred, these motivations are not necessarily related to bringing robots into the home.

Second, the habitats where robots do exist, e.g., laboratories, science fiction, and technology fairs are considerably different from the habitat of the home. Images of robots from these habitats enter popular culture as idealistic or premature promises. These act to perpetuate stereotypes, taint perceptions, and sell concepts that are extremely difficult to realise.

Third, adaptation means that the organism has a historical lineage in the given habitat. Robots in their current guises have no such lineage in the home. This raises the question of how do robots evolve? What are they currently being adapted to? And how might a lineage start in the domestic habitat?

A more applied approach to adapting robots to the home can begin by breaking the process down into three themes: functional adaptation (what robots do), form adaptation (how robots look), and interactive adaptation (how we interact with robots). In reality, it is through a complex combination of these three elements that any domestic object finds its value. However, for many (proposed domestic) robots these factors remain quite disparate research or conceptual themes.

\section{Functional adaptation: The niche}

Building on the ideas of the animal ecologist Charles Elton, ontologists Barry Smith and Achille Varzi liken the world of functional niches to "a giant evolutionary hotel, some of whose rooms are occupied (by organisms which have evolved to fill them), some of whose rooms are for a variety of reasons unoccupied but can become occupied in the future" $(1999$, p. 4). Taking the idea of this "evolutionary hotel" into the realm of robots, we could imagine a room inhabited by industrial robots that have filled a niche by delivering cheap and accurate labour. Another room might be inhabited by military robots whose niche is operation in dangerous or inhospitable environments. There might be a science fiction room with futuristic spectacular robots or a room for technology fairs occupied by shiny humanoid robots. Except for the occasional vacuum cleaner, the rooms that represent the home remain mostly empty; the robot is yet to find a genuine functional niche in this habitat.

All domestic products have been designed to fill niches-from utilitarian roles such as white goods, to more complex blends of aesthetics and emotive value, such as Philippe Starck's Juicy Salif lemon squeezer. The lack of a plausible and cost-effective domestic function for the robot could be attributed to the unique place it holds in our popular imagination. Combining the ancient fantasy of artificial life with modern practical applications such as the saving of labour, the robot provides both a tangible and captivating research goal and a spectacular future imaginary. The complexity of the challenge and the power of the dream provide a value that has allowed for the robot to escape from the rules that apply to other future domestic products.

Niches are about specialisation, of taking advantage of skills or traits to outdo the competition for a specific environment-many concepts for domestic robots, such as Sony's robotic dog AIBO, simply attempt to replicate established occupants of a niche such as pets. As discussed above, these post-utility roles are complex having evolved through countless generations of artificial selection; it is unlikely that this success could be replicated within a few generations of technological development. Robots excel at programmed, rational, repetitive, and predictable behaviour; these traits are at odds with the random and complex behaviour of animals that make them good companions.

A more traditional proposal is to build on the lineage of utility devices in the home through increased levels of automation. This approach has obvious appeal but in reality the concepts are immediately exposed to the basic household rule of cost-versus-benefit. The simple labour-saving 
devices have already been built in the form of white goods-the necessary mechanical complexity to complete the remaining domestic tasks (such as shirt-folding or dishwasher-emptying) means that it is unlikely that in the near-future the benefits will ever outweigh the costs, yet labour-saving remain one of the most common functions proposed for domestic robots.

For robots to establish a genuine niche in the home, it would be judicious to base the function on what the underlying technology excels at, not to simply replicate existing occupants such as pets or to blindly follow the stereotypical roles formed by years of depictions in popular culture.

\section{Form adaptation: Form follows fiction}

In his analysis of the evolution of domestic life, Witold Rybczynski points out that the various inventions that contributed to human comfort at the end of the nineteenth century did not have a profound impact on the appearance of the home, "the changes that did occur were due to fashion and popular taste." (1986, p. 173). He observes that during this time of great engineers, there was no obligation to apply an engineering aesthetic-rather the interiors of steamships, trains, and tramways always took comfortingly familiar forms (Rybczynski, 1986, p. 174). This observation sits neatly with the notion of adaptation; that these new technologies, while alien in concept, were made familiar and acceptable by designing their appearance to fit in with the existing landscape: Form follows familiarity.

As with function, those currently giving form to robots are commonly more influenced by their historical representations than by the styles of the contemporary domestic habitat: Form follows fiction. In their defence, it could be argued that as the domestic environment is built almost exclusively with the form of humans in mind (e.g., staircases, door handles, tools, etc.) then it follows that any robot intended to operate in this space should adopt the same form (Behnke, 2008). Another justification put forward is that it would be more natural for humans to interact with humanoid than abstract forms (Brookes, 1996). While there is an undoubted logic to both of these arguments, they are undermined when the fundamental issue of function is raised. The stereotypical robot has such a secure place in our fictional futures that, as described above, real function can be overlooked, and without a clear function, designing an appropriate form is impossible. Therefore, this fictional heritage continues to influence the form of many robots. As a fiction, real-world issues of taste, cost, and context can be ignored allowing form-givers a freedom to either exaggerate the mechanical aspect by exposing metal, gears, and cables or to cover workings with sleek, shiny, stylised futuristic plastic and chrome.

By applying a normative product design methodology-adapting the robot to the domestic landscape and incorporating clear functional purpose in the design process, it is possible to imagine entirely different forms for robots in harmony with the contemporary home and the tastes of the people who live there.

\section{Interactive adaptation: HumanPerson/robot interaction}

How we might interact with artificial entities is another key theme in robotic research. The motivation often begins with the prediction that robots will soon become a ubiquitous part of modern society (Gates, 2007), and that robots therefore "must be easy for the average citizen to use and interact with" (Breazeal, 1999). In her paper, Breazeal (1999) describes the importance of designing effective human-robot interfaces so that "untrained users can make safe and efficient use of the robot." Apart from a brief nod to humanoid robots for care applications, the paper does not suggest what the use of the robot might be. As a consequence a very general notion of interaction is described-another example of stereotypical and mythical notions of robots influencing research and resulting a very generic idea of human-robot interaction. Many social robots operate in the highly artificial conditions of laboratory open houses. While these choreographed displays can lead to successful papers, conference presentations, and live performances, they tend to ignore the complex reality of human interactions-to develop a meaningful interaction between humans and robots it is imperative to first know its function and the context in which the interaction is taking place, otherwise the event is simply a showcase. 
The fundamental factor for anyone planning to develop technology for domestic use is that people and the desires that shape their surroundings and possessions are highly complicated and transient. Designing familiar domestic products is relatively straightforward as there are lineages, functions, trends, and values that inform how they might look and behave. For robots, all of these issues are still open to interpretation. The maladaptation issue mostly stems from the observation that fictional and mythical ideas of robots continue to exert huge influence on research and development-while the concepts are frequently are engaging and alluring, they remain essentially inappropriate for the domestic habitat. If robots are to enter into our homes, we must begin by dismantling the stereotypical and romantic concepts that pervade; only then will genuine functional niches be identified and filled with suitable forms and modes of interaction.

\section{Hypothetical domestication - speculative design}

The following describes a speculative design approach to technological development and domestication. First though, I will address the complex issues surrounding the definition of speculative design, as it has much in common with other design-related research such as critical design $^{3}$, discursive design ${ }^{4}$, design probes ${ }^{5}$, and design fictions ${ }^{6}$.

There is much overlap between these practices. The differences are subtle and based primarily on geographical or contextual usage; all remove the constraints from the commercial sector that define normative design processes; use models and prototypes at the heart of the enquiry; and use fiction to present alternative products, systems, or imaginaries. Speculative design shares these aspects while employing the more specific strategy of extrapolating emerging technological potential to inform the design of the future or alternative worlds. It is analogous to speculative biology, coined by the geologist Dougal Dixon and exemplified in the book, After Man: A Zoology of the Future (1981). It begins with an introduction by the zoologist Desmond Morris, describing the strengths of this approach:

By introducing us to fictitious examples of these factual processes [adaptation, specialisation, convergence and radiation], his book is not only great fun to read but also has real scientific value. The animals on these pages may be imaginary, but they illustrate

\footnotetext{
${ }^{3}$ Critical Design uses speculative design proposals to challenge narrow assumptions, preconceptions, and givens about the role products play in everyday life. It is more of an attitude than anything else, a position rather than a method. There are many people doing this who have never heard of the term 'critical design' and who have their own way of describing what they do. Naming it critical design is simply a useful way of making this activity more visible and subject to discussion and debate. Its opposite is affirmative design: design that reinforces the status quo (Dunne and Raby, 2007).

${ }^{4}$ We define Discursive Design as a category of product design that treats artefacts principally as transmitters of substantive ideas, rather than as mere instruments of utility. Discursive Design is a rubric beneath other existing, similarly- minded approaches that exist, such as Critical Design and/or Design for Debate (Tharp \& Tharp 2012).

${ }^{5}$ Philips Design Probes is a dedicated 'far-future' research initiative to track trends and developments that may ultimately evolve into mainstream issues that have a significant impact on business. The probes generate insights from research in five main areas: politics, economic, culture, environments, and technology futures. With the aim of understanding 'lifestyle' post-2020, the programme aims to identify probable systemic shifts in the social and economic domains likely to affect our business and create intellectual property in new areas. It challenges conventional ways of thinking to come up with concepts to stimulate debate. Deliverables range from scenarios and narratives to the creation of experience prototypes and IP fortressing (Philips, n.d).

6 The deliberate use of diegetic prototypes to suspend disbelief about change. That's the best definition we've come up with. The important word there is diegetic. It means you're thinking very seriously about potential objects and services and trying to get people to concentrate on those rather than entire worlds or political trends or geopolitical strategies. It's not a kind of fiction. It's a kind of design. It tells worlds rather than stories (Bosch, 2012).
} 
vividly a whole range of important biological principals. It is this - the way in which he has perfectly balanced his vivid dreamings with a strict scientific discipline - that makes his book so successful and his animals so convincing and, incidentally, so superior to the often ridiculous monsters invented by the cheaper brands of Science Fiction. (Dixon, 1981, p.9)

Speculative design operates in a similar way, but rather than basing the proposals solely on scientific laws and principles, it also incorporates a sociocultural element- the role of fashion, trends, and human behaviour in shaping everyday life. The aim is not to predict, sensationalise, politicise, demonise, or canonise specific technologies or agendas. Instead, to place emerging technologies into real-life contexts, communicating how these would be manifest through tangible evidence such as props, videos, images, scenarios, vignettes, and stories. These allow the viewer to contemplate what life might be like in the depicted future or alternative present.

The following projects by staff and students at the Royal College of Art (RCA) exemplify this approach applied to robots. They have been chosen to represent one or more of the adaptation factors described above. I have also included a project by the artist-engineer Natalie Jeremijenko that, while not being based on speculative design practice, does provide valuable insights into other routes of adaptation. For each example, I will also discuss the presentation methods and how they communicate the theme or point of the project.

\section{RCA student project-Living with robots (2011)}

I began with a student project that had ran over four weeks in the Design Interactions (DI) department at the RCA. Sixteen first year students on the MA programme participated in the project, funded by Intel Research Laboratories.

The brief was intended to direct the students towards the specific problems and opportunities raised by a design approach to domestic robots - specifically form, interaction, and contextual considerations. The next subsection contains the brief, and this is followed by two student projects that resulted from the brief.

\section{The Brief}

In an essay for Scientific American (2007), Bill Gates drew an analogy between the emergent computer industry in mid-1970s and the state of the robotics industry today, coming to the conclusion that there will soon be a robot in every home. This is a prediction that has been made many times over the past 70 years.

The question remains, "What will these robots do in the home?" Many proposed robots focus on formidable engineering problems or choreographed stage demonstrations, ignoring the complex rules of the domestic landscape.

By making a taxonomic shift to view the robot as a product rather than a technology, it becomes exposed to a whole different set of rules and expectations to those that currently inform and direct robot development. This contextual shift-from the screen and laboratory to the domestic and the everyday introduces new ways of thinking about robots, our relationships and interactions with them and their meaning, not as visions, props, or demos but as real things in our homes:

1. What would robots do in the home? Roboticists rarely answer this fundamental question with tangible propositions. Bear in mind the strengths of robots but also their weaknesses.

2. How could we and our homes adapt to a robot's needs? We shape elements of the home to the special needs of pets, but how might a home designed for people and robots look?

3. How could robots adapt to the home? Social roboticists explore human-machine interaction but rarely address where that interaction takes place. Methods of interaction are then mostly based on the robot adopting human techniques. The purpose of an 
interaction defines its nature. What would be a more appropriate method of communicating with domestic robots?

4. How can we begin to understand the ethical implications of bringing robots into the home? Ethical issues are hotly debated in the field of military robots, but in the home, robot ethics have been neglected. What would it mean, for example, to delegate caregiving tasks to a machine?

Defining the word 'robot' is a challenge. For the purposes of this project we will use the broadest meaning possible:

- It can sense its environment.

- It can compute decisions based on this sensory information.

- It can act on these decisions (e.g., through mechanical or electronic means).

These criteria suffice from a technical perspective, but fail to reflect the mythical or emotive factor commonly associated with robots. To the technical definition the following can be added:

The complexity or sublimity of either the sensing, computing, or mechanics should elevate the status of robotic object above that normally ascribed to machines or products.

Note: The form of the robot is completely open to interpretation.

To Design:

Begin by choosing one subject from above.

The goal is to design a domestic robot and to rethink the robot based on complex human needs and desires, the rules of the domestic space, and the strengths of robot technologies. Don't get distracted by stereotypes as they often ignore these points.

Neo-naturalists by Neil Usher (2012)—A new niche

Usher's (2012) project approaches the subject of robot function by taking advantage of the (functional) traits normally associated with industrial robots and deploying them in original and thought-provoking everyday contexts.

His working prototype, Nimbus MkIII, is designed to automate pareidolia ${ }^{7}$, in this case looking for human faces in clouds. Two cameras, employing face-recognition software, tirelessly scan the sky. They move rapidly through a choreographed sequence of moves designed to minimise the chances of a cloud-face being missed. Captures are automatically stored on a hard-drive informing the owner of a successful event via a flashing light. By using face-recognition software, the robot can be customised to search for a specific face and to define the accuracy of decision-making algorithm. This feature has to potential to greatly increase the rarity of the special cloud making the quest more magical; it might operate for many years without success but one day...

Other robots in the series scan fields for four-leaved clovers or autonomously locate and film wild mammals for home entertainment.

The strength of the project lies in the psychological and emotional connection we might have with the goal of the robot. Many of us, particularly in childhood, will have searched endlessly for four-leaved clovers or searched the sky for faces. By delegating these tasks to robots it gives them new functional roles that play to their strengths - as on production lines they will be far more capable than humans at fulfilling the designated tasks. Usher (2012) designed a complex mechanical system that provided the robot with an engaging and hypnotising movement, convincing the audience of its capabilities and allowing them to indulge in the imaginary aspect of its function.

${ }^{7}$ The psychological phenomenon of ascribing significance to random or vague patterns in nature 
While this project is playful, it successfully presents robots in a different light, moving beyond military and production usage and stereotypical labour-saving roles to suggest more romantic and aesthetic roles in everyday life.

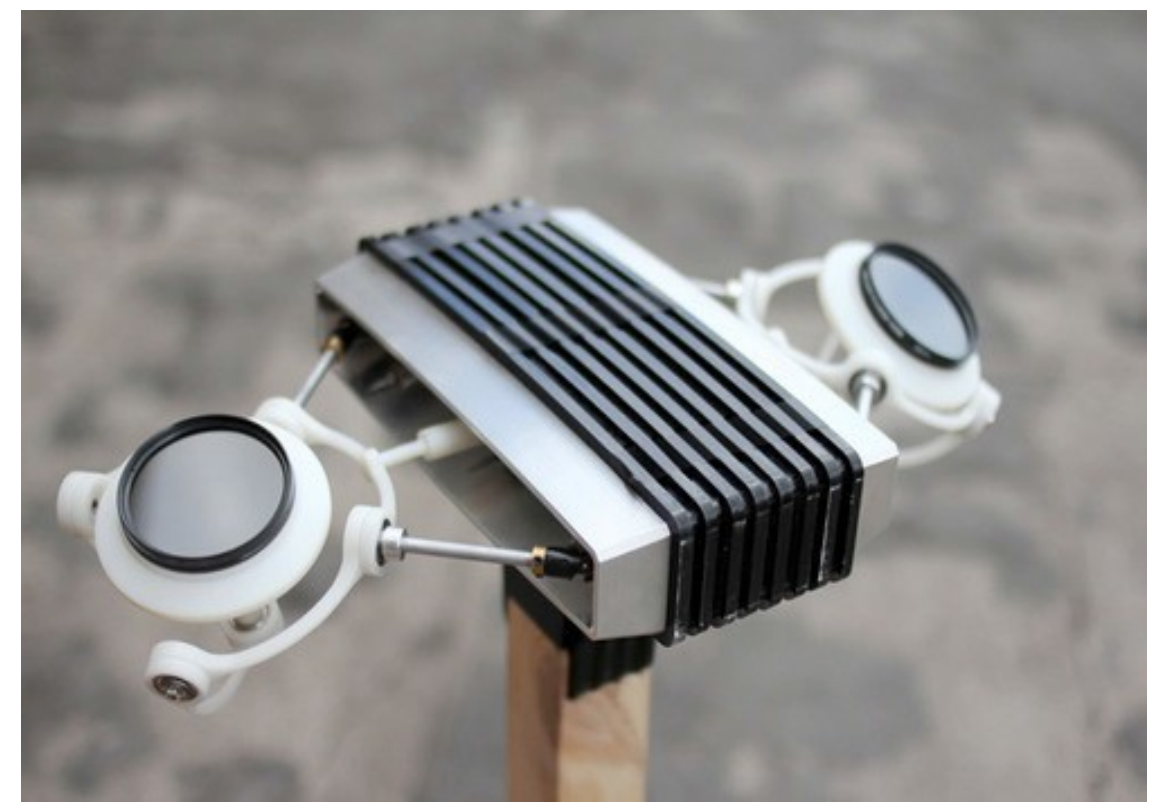

Figure 2. Neo-naturalists - Nimbus MkIII, Neil Usher

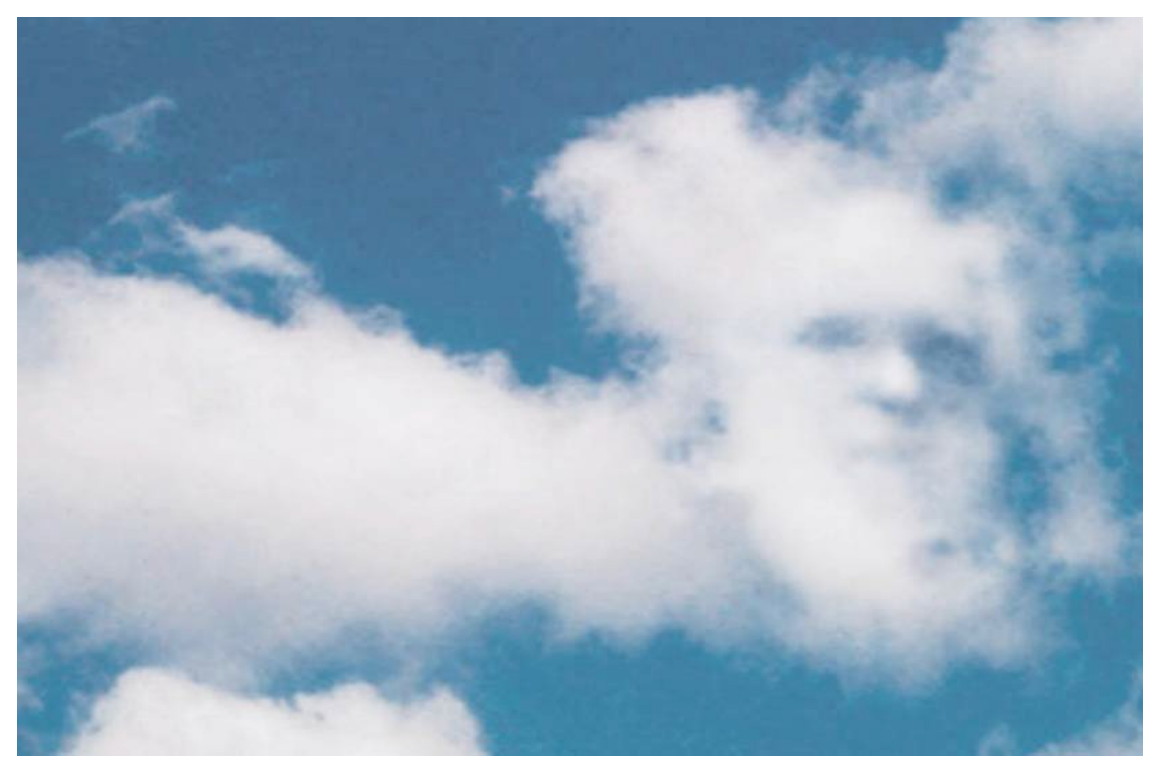

Figure 3. Neo-naturalists - Random face, Neil Usher (2012) 
Auger, Living with Robots

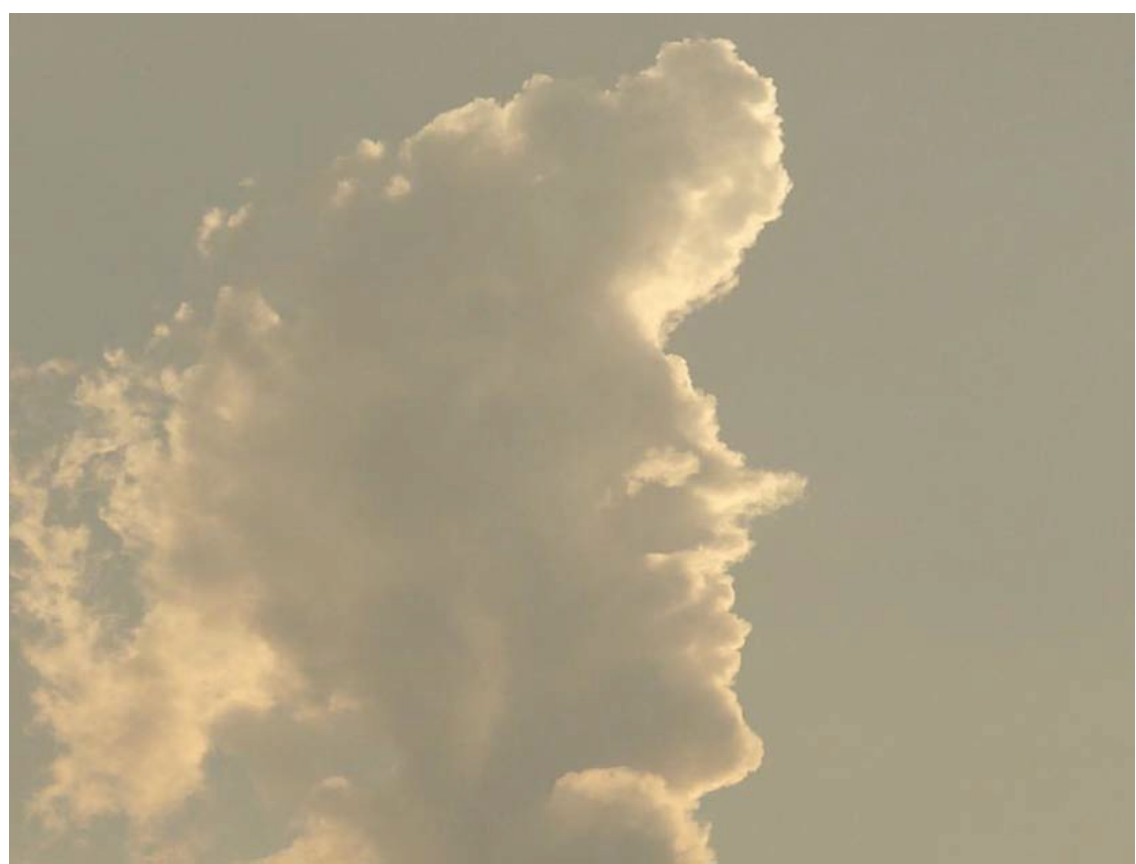

Figure 4. Neo-naturalists - Elvis cloud, Neil Usher (2012)

With Robots by Diego Trujillo (2011)—Adapting the home to accommodate robot needs

With Robots builds on familiar notions of domestic labour-saving rather than adapting robots to the home. Trujillo (2011) simply modifies the home to be sympathetic to the limitations of robots. This lateral thinking provides simple solutions to the complex mechanical problems that commonly become the focal points of research projects-rather than develop a highly complex robot hand that can grasp cup handles, why not simply redesign the cup?

With Robots also exemplifies of how a design approach can communicate complex ideas and observations in succinct and engaging ways. It is not always necessary to research robots through expensive time-consuming physical prototypes; ideas can be explored through imagery and rough mock-ups. Here Trujillo (2011) created a series of photographs, each making a particular point. Look closely at the images below and normal domestic life begins to appear slightly odd as subtle compromises that make the home more hospitable to robots. This oddness encourages the viewer to draw their own conclusions as to why things are slightly uncanny: the dinner plate rotated $90^{\circ}$ out of position; the cupboard with drawers clumsily removed and cups with odd handles; the aestheticised optical tags on the sheet; and the perfectly sliced slab of meat. These suggest the presence of something robotic in the house and although we never see it, we are drawn into the fiction in subtle and intelligent ways, encouraging our imagination to take over and fill in the gaps. Trujillo (2011) describes realistically how the domestic landscape would inevitably undergo subtle changes during the incorporation of the robot. The aesthetic treatment of the project and its original approach to domestic robots has led to With Robots being featured on several popular websites and blogs, such as Wired (2011), BLDGBLOG (2011), and Dezeen (2011). 


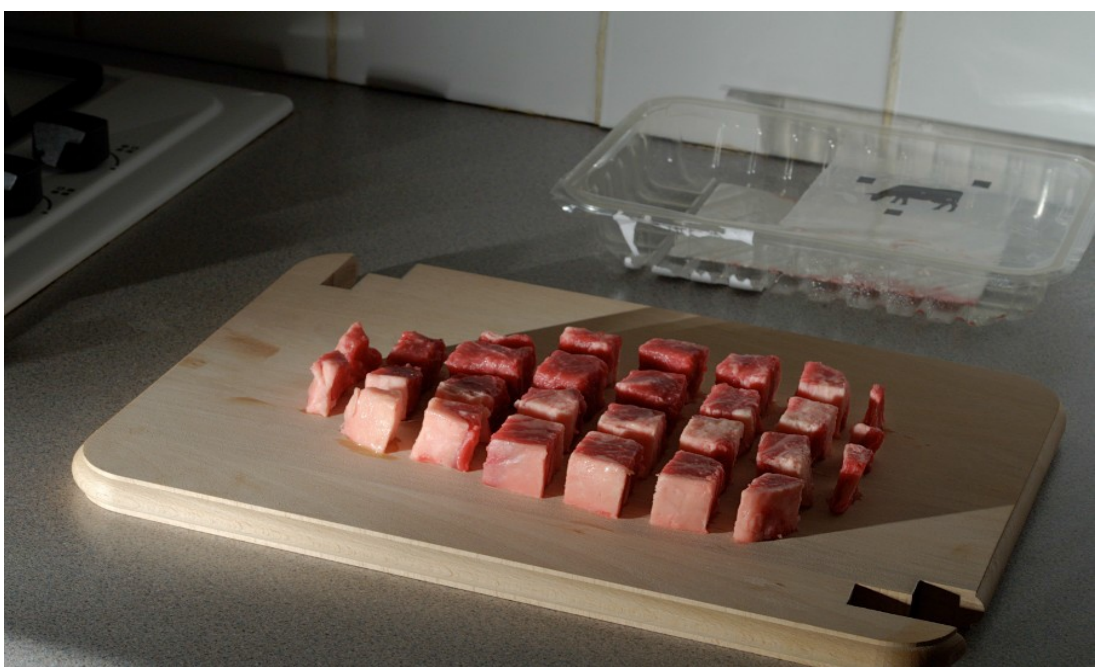

Figure 5. With Robots - Cooking, Digo Trujillo (2011):

Cooking robots have been promised for more then 60 years, ranging from Falks robotic toaster to the Jetsons' Rosie maid-bot. How desirable is robot precision in the kitchen? The situation shows how meat has been precisely cut into cubes without leaving any cut marks on the chopping board. The board its self has notches to facilitate robot interaction.

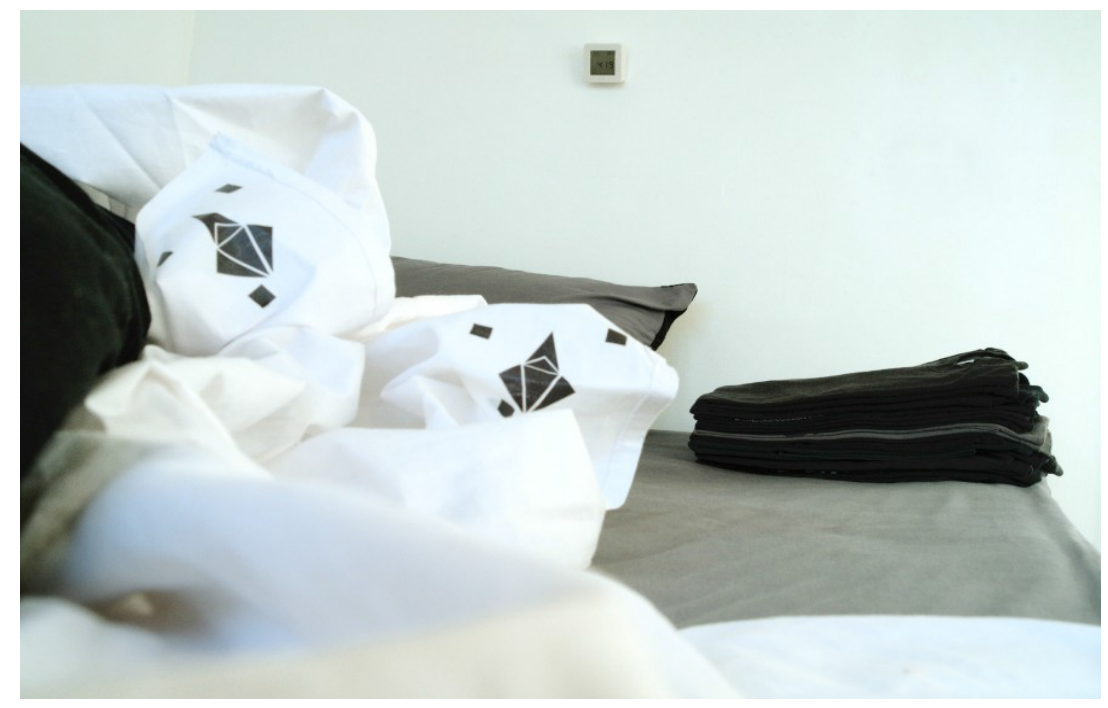

Figure 6. With Robots - Folding, Diego Trujillo (2011)

Robot-friendly bed sheets were designed to assist with a computationally demanding task. For the humans it means having a foreign symbol printed onto their bed sheet. In the background we see a small clock reading 16:19 suggesting the robot has been folding laundry for a very long time, even with the help of the tags. 


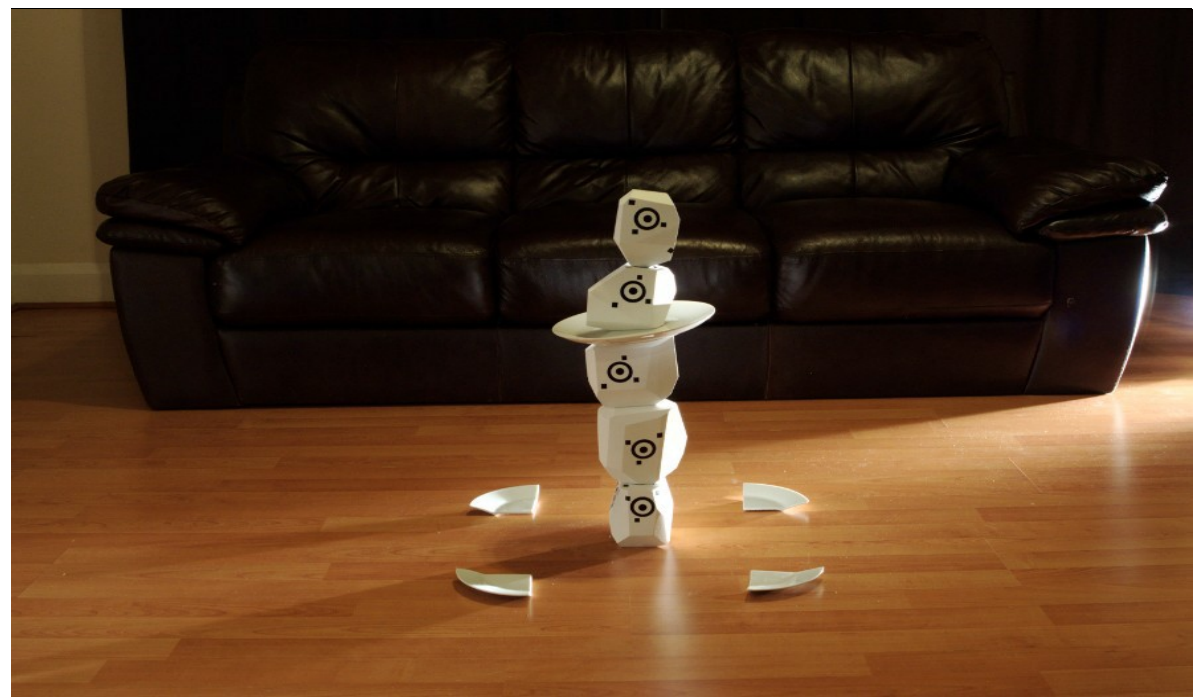

Figure 7. With Robots - Learning Diego Trujillo (2011)

Every living space is different, not only in the architectural layout but also in the tasks that the tenants require the robots to do. For this reason, robots ship only partially programmed so that through a learning algorithm they might adapt to the home they operate in. To accelerate the learning process, special learning tools have been designed to help the robot integrate to a $3 \mathrm{D}$ environment. This picture image shows a living room after a robot self-training session. We can see it has now mastered the physics of equilibrium. It is also evident that it has mistaken one of the house's dinner plates that it has broken with robotic precision to complete its piece. This scene intends to show what it would feel like to have objects that are useful only to robots in our house.

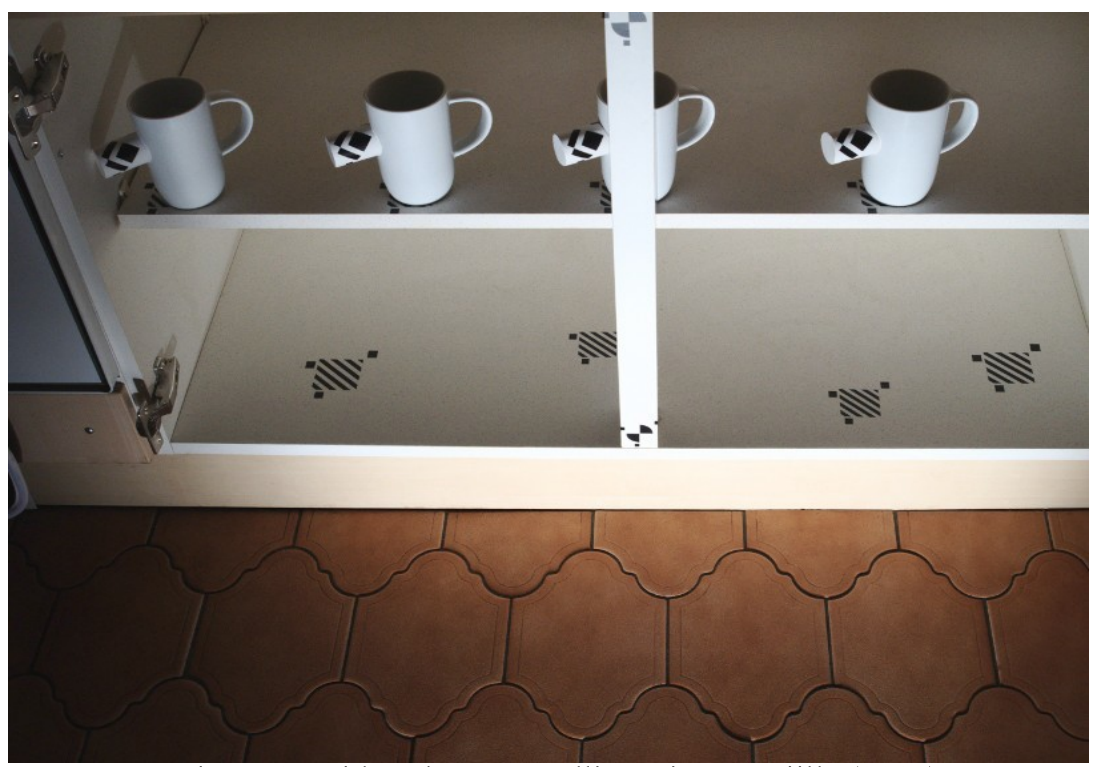

Figure 8: With Robots - Handling Diego Trujillo (2011)

Setting the table is another task robots might be doing, having everything ready for when the owner comes home. The plate does not require a "plate tag" printed on it, the tag has been replaced by a notch on the edge indicating that this object is a plate (Figure 9). The notch also doubles as a holding point; it makes us wonder on the shape of the tool the robot uses to manipulate this object. The edges of the table are marked telling the machine where the limits are. In the scene presented, the robot has made a mistake and placed the cutlery rotated by $90^{\circ}$. 
Auger, Living with Robots

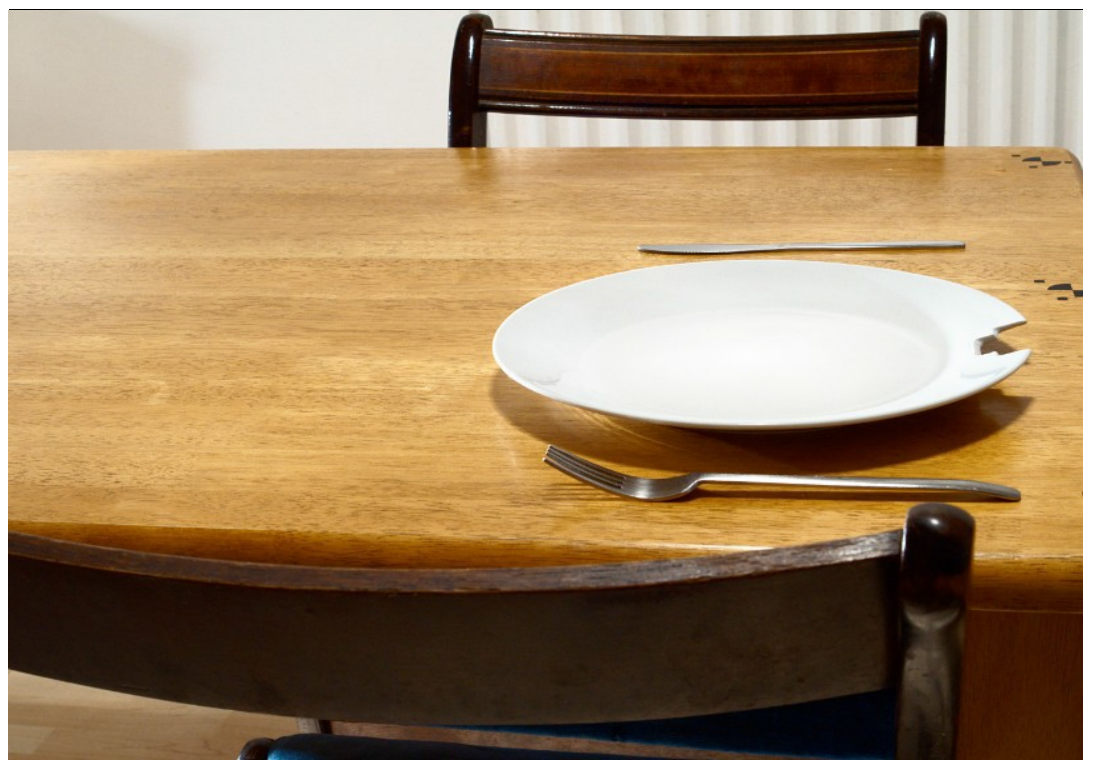

Figure 9. With Robots --- Serving Diego Trujillo (2011)

How might robots manipulate objects? A cup with a robot friendly handle was designed. This object reveals a lot about the relationship between humans and robots; it creates a tension between the robotic and the human handle. The handle could become a design feature or it could be badly received, considered ugly and uncomfortable. The cupboard in which these cups rest has also been altered to accommodate the robot; not only are there tags marking the position of objects but the doors have been removed.

\section{Dunne and Raby: Technological Dream Series: No. 1, Robots (2007) - Form follows familiarity}

The designers (and professors/readers in Design Interactions) Dunne and Raby took the opposite approach when dealing with the subject of domestic robots. Their robots are adapted to the home, and as such, more resemble pieces of furniture than the forms we have come to expect. Any concept that challenges a preconception will at first appear odd, but in this case the oddness is helpful - it encourages the audience to examine further why the designers label these strange objects as robots.

Behind their surprising facades, Dunne and Raby's robots exhibit more familiar behaviours and functions, but these are tweaked in very human ways: Our fears, established by years of negative portrayals in science fictions, are mollified by making the robots needy and subservient; current issues about privacy and data are dealt with by employing the latest biometric techniques, which in practice require the owner to stare into the robots 'eyes' for extended periods of time; furniture is adapted to accommodate new technologies, appearing familiar but with advanced functionality; and technological interactions take place in odd but intimate ways.

The project offers a fresh perspective domestic robot forms and interactions. The obvious first impression is that they do not look like robots, but they are exquisitely designed objects that, due to the cables and interactions in the images, look somehow 'functional' and due to the materials and scales, somehow 'domestic'. The object explanations describe familiar robot functions but accessed through new interactions that address commonly neglected emotional issues - as Dunne and Raby (2007) describe, the "objects are meant to spark a discussion about how we'd like our robots to relate to us: subservient, intimate, dependent, equal?" The key strength of the project is that it shatters the established version of the robot, dismantling expectation and allowing for a complete re-thinking of the subject. 


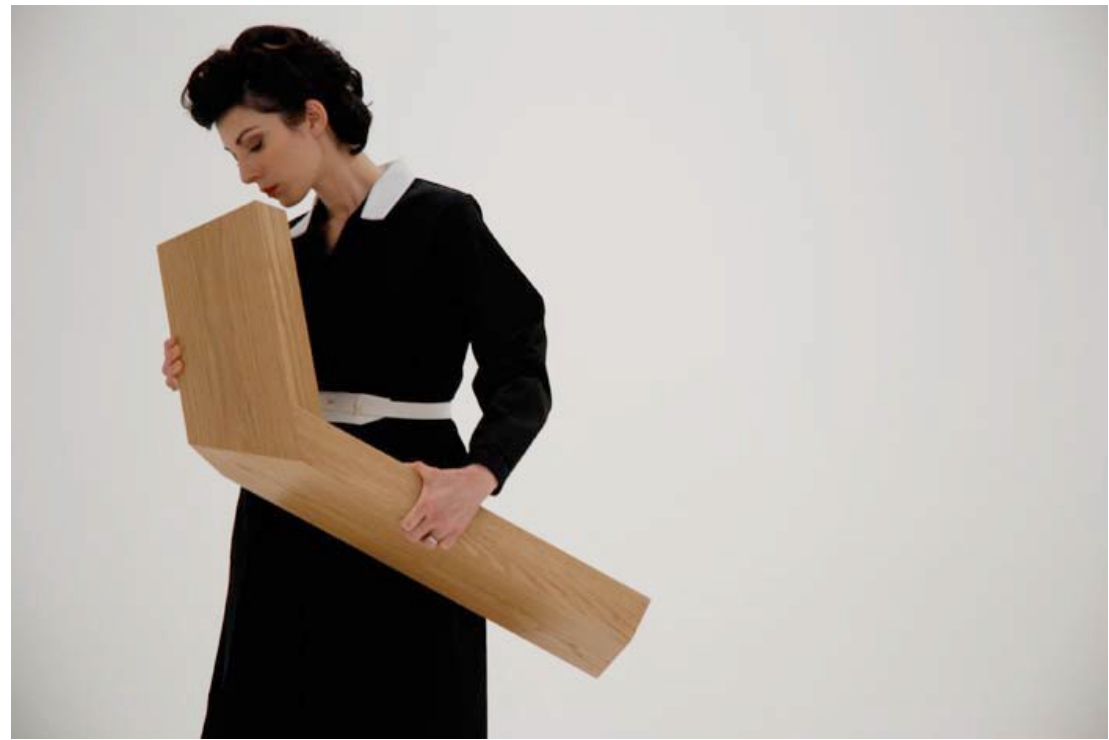

Figure 10. Robot 3 - from Technological Dream Series No. 1 (Dunne and Raby, 2007)

More and more of our data, even our most personal and secret information, will be stored on digital databases. How do we ensure that only we can access it? The robot is a sentinel; it uses retinal scanning technology to decide who accesses our data. In films, iris scanning is always based on a quick glance. This robot demands that you stare into its eyes for a long time; it needs to be sure it is you. On another level, it asks what new forms of furniture might evolve in response to future technological developments.

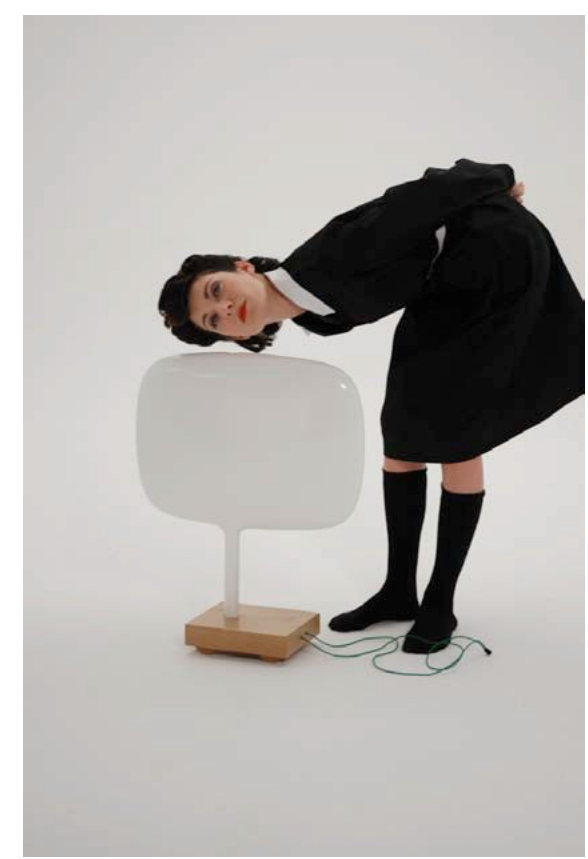

Figure 11. Robot 4 - from Technological Dream Series No. 1 (Dunne and Raby, 2007)

The robot is very needy. Although extremely smart, it is trapped in an underdeveloped body and depends on its owner to move it about. Neediness is designed into very smart products to maintain a feeling of control. Originally, manufacturers would have made robots speak human languages, but over time they will evolve their own language. You can still hear human traces in its voice. 
Auger, Living with Robots

James Chambers: Attenborough Design Group (2010) - Form follows existing

A more subtle and perhaps logical approach to robot form and interaction is to update existing artefacts with robot related technologies such as sensors, computation, or kinetics. This takes advantage of our familiarity with existing objects and therefore circumvents the issue of maladaptation - the object is already adapted.

In his Design Interactions graduation project, Attenborough Design Group (ADG), James Chambers (2010) postulated on the hypothetical existence of a research group within the electronics company Texas Instruments, led by the famous natural historian, cultural icon, and filmmaker, David Attenborough. Objects developed by the group, while based on orthodox and existing products, are given new behavioural rules based on survival instinct and inspired by complex evolved techniques in the animal kingdom. These new product behaviours enhance both the chances of physical survival through novel defence mechanisms and emotive survival through eliciting a deeper relationship with the owner. This latter element was achieved through iterative behavioural prototyping, specifically based on anthropomorphising the various movements to elicit either sympathy (the Gesundheit Radio and Floppy Legs) or wariness (Anti-Touch Lamp).

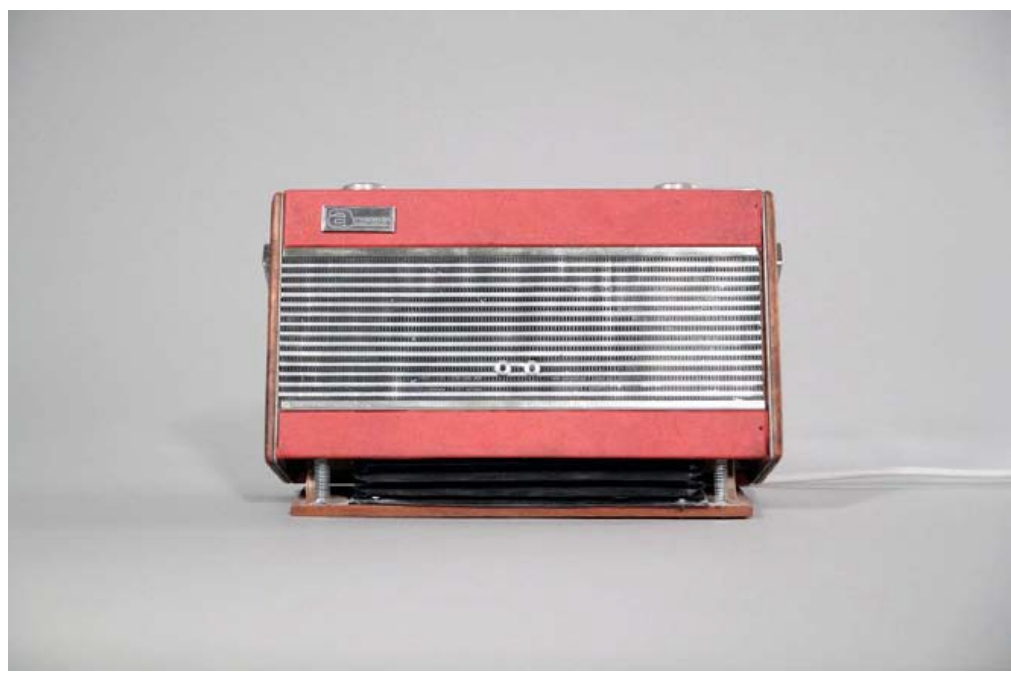

Figure 12. ADG - The Gesundheit Radio, James Chambers (2010). An internal mechanism triggers a sporadic anthropomorphised sneezing behaviour, which was developed to protect early fragile microprocessors from dust.

There are two key aspects to the success of Chamber's project. The first aspect is the choice of David Attenborough as head of his fictional research studio. This not only captures the attention of several generations of U.K. television watchers due to his unique social standing but also presents a captivating logic to the design and behaviour of the prototypes, in turn justifying the benefits of the studio's approach. The second aspect is the object's kinetic behaviour. This was perfected through many experiments and iterative prototypes while being aimed at creating a more emotive connection between the owner and the object: The hard drive appears to struggle when lifting itself in reaction to the spilt coffee and settles back asymmetrically down like a camel offering itself for a ride; the radio rocks back and forth expelling dust from the small 'nostrils' on its façade, this happens randomly and unexpectedly suggesting agency and resulting in a heighted emotive value due to the unpredictability of its behaviour; the lamp sways organically in reaction to something getting too close to its fragile bulb (i.e., follow the link to the short videos describing each of the objects: http://vimeo.com/user1333671). 


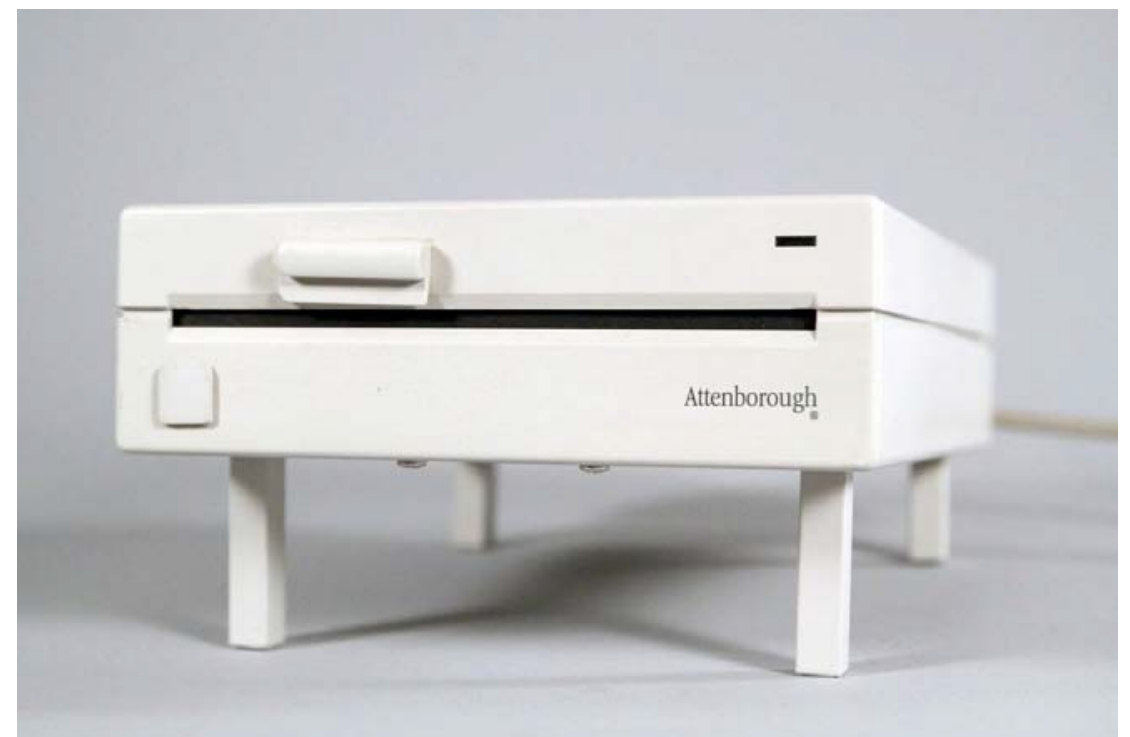

Figure 13. ADG - Floppy Legs, James Chambers (2010). The portable floppy disk drive stands up if it detects liquid nearby.

The 'robotification' of familiar products suggests a very likely route through which robots could enter the home- existing lineages provide clear directions for product evolution, functional values are already established, and forms already fit into the domestic landscape, as do modes of interaction. The challenge is to find ways for the robotic factor to enhance or augment one or more of these elements to give the 'robotic object' a value above that of their predecessors.

\section{Natalie Jeremijenko: Feral Robotic Dogs (2005) - functional interaction}

"OUT THERE, in happy family homes, in the offices of corporate executives, in toy stores through out the globe, is an army of robotic dogs. These semi-autonomous robotic creatures, though currently programmed to perform inane or entertaining tasks: begging for plastic bones; barking to the tune of national anthems; walking in circles; are actually fully motile and AWAITING FURTHER INSTRUCTIONS." (http://www.nyu.edu/projects/xdesign/feralrobots/projectindex.html)

The artist-engineer Natalie Jeremijenko (2005) continued with her theme of creating critical political interventions and events with this project. As with Chamber's (2010) project, she exploited existing products on the market - in this case entertainment robots, to "provide a readymade, inexpensive, and highly distributed hardware platform." With 'off the shelf' robotic dogs as a starting point, Jerimejenko then used an open source network to build a community of activists to hack into them and expand their capabilities through the addition of new sensors and programming. The project involved releasing a pack of modified robotic dogs in areas of community interest to search out and raise awareness on local environmental health issues.

The project highlights two novel methods: the addition of environmental sensors to test for toxins adds enormous functional value to the robot-no longer is it rendered predictable and ultimately unentertaining by the limits of its programming and sensory capabilities, but it can seek out and communicate potential environmental dangers - the random nature of these result in a robot that will never become predictable. Second, the presence and allure of robots and robotic dogs in popular culture make the project extremely appealing to both young people (as potential participants in the project) and the media. As with corporate robots, such as Honda's Asimo, the Feral Robotic Dogs are effectively exploited as extremely press-friendly objects to ultimately communicate or raise awareness about other issues. The notion of adaptation still works here when 
we acknowledge the robots are not being adapted to the home but rather the mediagenic habitat of imagery, provocation and story-telling - robots already excel in this domain, but Jeremijenko succeeds in deflecting the emphasis onto the environmental issues that were at the heart of the project. Their interactions, first with the local environment and then with the media, provide the function for the robots and give a value far beyond that of the original devices.

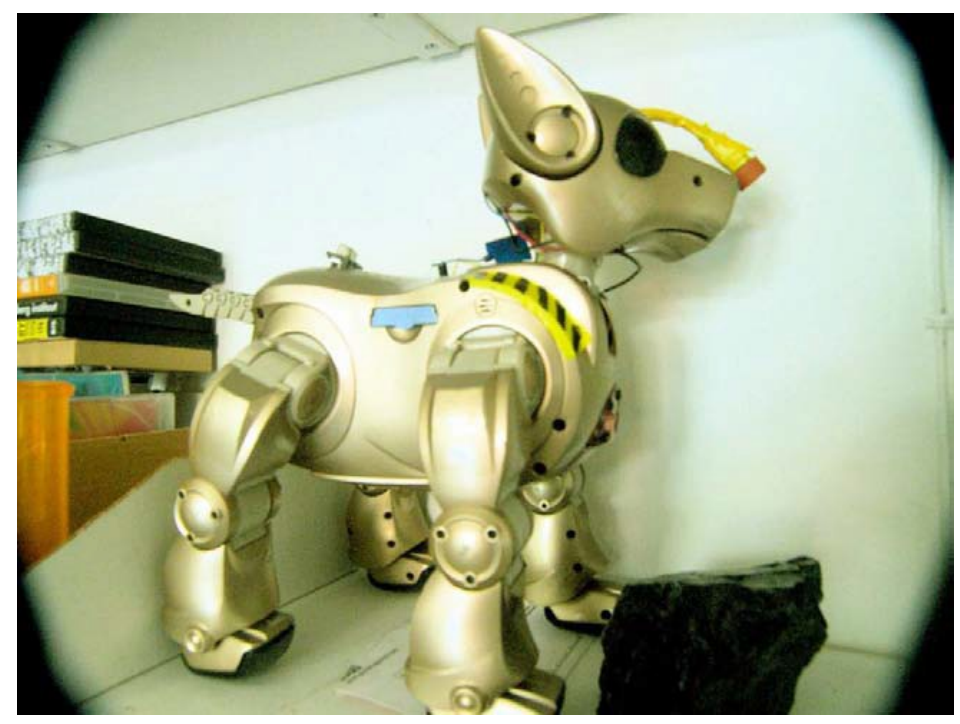

Figure 14. Feral Robotic Dogs, (Natalie Jeremijenko, 2005) http://www.flickr.com/photos/jeffreywarren/2595685326/

Carnivorous Domestic Entertainment Robots, Auger-Loizeau (2009)

I will conclude with a more detailed examination of a speculative design approach to robots. Carnivorous Domestic Entertainment Robots (CDER) was produced in collaboration with designer Jimmy Loizeau and engineer Alex Zivanovic. The project was commissioned as part of the Engineering and Physical Sciences Research Council (EPSRC) funded research project Material Beliefs ${ }^{8}$. We initially collaborated with Bristol Robotics Laboratory (BRL), whose research into alternative energy sources and energy autonomy in robots provided the inspiration for our project. In generating their own energy, BRL's robots, i.e., the EcoBot series and SlugBot, used a microbial fuel cell ${ }^{9}$ (MFC) with a primary focus on its development and optimisation. These fill a niche as definitive laboratory robots, meaning that modes of interaction, aesthetics, and behaviour were informed by the requirements of that habitat. The project provided a $n$

${ }^{8}$ Rather than focusing on the outcomes of science and technology, Material Beliefs approaches research as an unfinished and ongoing set of practices happening in laboratories and separate from public spaces.

The lab becomes a site for collaboration between scientists and engineers, designers, social scientists, and members of the public. Alongside existing research activity, such as collecting experimental data, writing academic papers, and funding proposals, the collaborations lead to a parallel set of outcomes including interviews, brainstorming, drawing, photography, filming, and discussion. The collaborations lead to the design of prototypes, which embed these parallel outcomes into something tangible. These prototypes are exhibited, transforming emerging laboratory research into a platform that encourages a debate about the relationship between science and society (Material Beliefs, 2013).

${ }^{9}$ Microbial fuel cell technology is employed to extract electrical energy from refined foods such as sugar and unrefined foods such as insects and fruit. This is achieved by extracting electrons from the microbial metabolic processes. (Bristol Robotics Laboratory, 2013) 
opportunity to experiment with how to migrate MFC technology into the home using notions of domestication. The outcome of the project was a series of five robots, each feeding off living organisms for electrical energy and built as semi-operational prototypes.

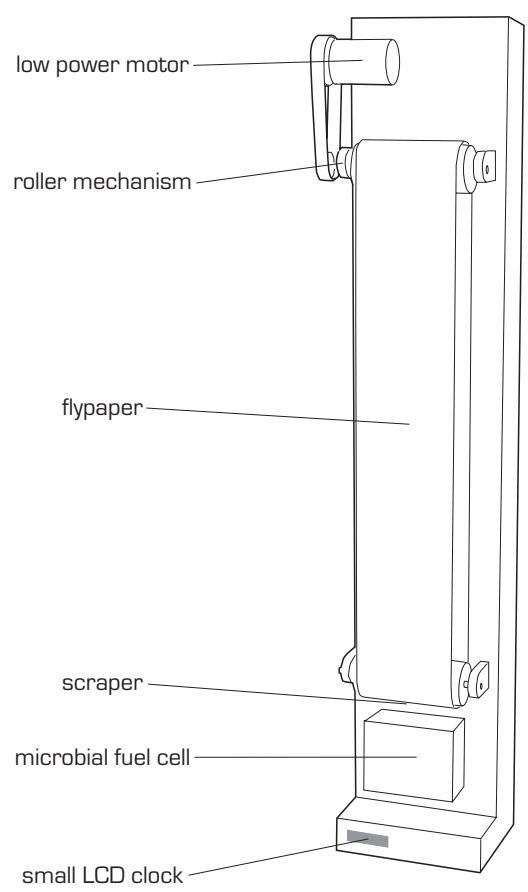

Figure 15. Flypaper Robotic Clock.

A rubber belt revolves slowly around two rollers on a vertical plane. This belt is covered in honey, which attracts and captures various flying insects. At the base of the roller mechanism a scraper removes any insects that have become attached to the belt and they fall into the MFC positioned below. This generates the electricity to power both the motor rotating the belt and a small LCD clock.

There is some basic sensing built into this robot related to seasonal change and its effect on the quantity of available insects. This means that the robot can partially hibernate during the winter months, continuing to tell the time through energy harvested during the summer months, but not wasting energy through rotating the belt.

The project consciously explored the three areas of adaptation described above: form, function, and interaction.

In terms of formal treatment, the robots sit somewhere between Dunne and Raby's more abstract Technological Dream Series and James Chamber's familiar ADG objects. Some of the objects are based on existing furniture such as the Robotic Lampshade and the Coffee-table Robot, while others such as the Flypaper Robotic Clock are more unexpected. They are all intended to exist as desirable domestic objects that would not look out of place in the contemporary home.

The utilisation of the microbial fuel cell for energy supply ruled out the majority of utilitarian functions commonly associated with domestic robots. We instead considered other common proposals-artificial companions and entertainment. By exploiting the narrative potential of the fuel cell, specifically its use of living organisms for energy, the consequential possibility of energy autonomy and the resultant living thing-we imagined a new category of object existing somewhere between a pet or houseplant as a normal domestic product.

BRL's Ecobot had no capacity for identifying and capturing insects, instead they were manually placed into the microbial fuel cell by the scientist. In giving life to the Flypaper Robotic Clock, it was necessary to adopt a more automated and aesthetic approach to its feeding, enhancing its perceived existence by reducing physical interaction to a minimum. By referencing the predatory techniques of carnivorous plants, in this case the Pinguicula genus, it was possible to create a visible low-energy technique for attracting and capturing prey. Interactions then, are mostly psychological and emotional. We also used the qualities of nurture we might experience from caring for pets and houseplants and the inevitable fear of death that comes with being responsible for living things. 

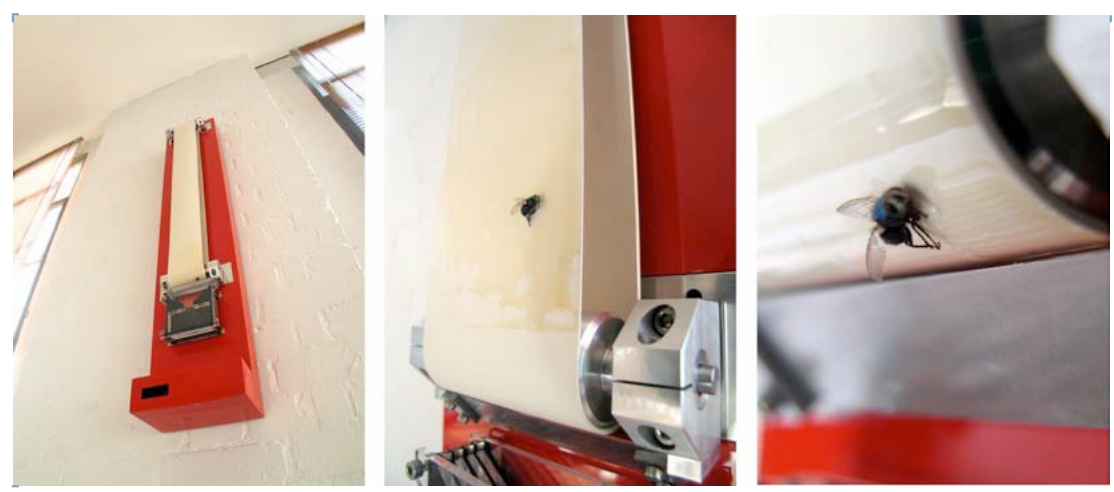

Figure 16. Flypaper Robotic Clock. A fly is buzzing around the room. With a Flypaper Robotic Clock this fly is no longer a simple nuisance but a participant in a live performance: Will it fly towards the clock? If so, will it land on the belt? Will it stick to the honey? Watch as it is slowly delivered to the blade. Will it escape before it gets there...?

Like Frankenstein's monster, the CDERs require human assistance to bring them to life, using either mains power or a standard battery to initially drive their predatory mechanisms. Once switched on, they begin to capture the biomass necessary for the fuel cells to generate electricity. To show their energy status, the robots have graphic displays, which might remain unlit for many months or even years, but they could turn on at any moment, keeping the owner engaged - just as a fisherman might watch a static float for hours on end in the anticipation that it will eventually dip into the water.

\section{Discussion}

The robot is a special subject due to its unique place in both popular and research culture. Why, after so many years of unrealised promises (to enter everyday life), does the latest version still succeed in generating huge media attention and captivating such a broad audience? I would suggest that while the robot has a clear raison d'être in the habitats of research laboratories, marketing, manufacture, and science fiction, its purpose in the home has always been based on mythology and profound promise - not reality — and is therefore confusing.

This paper is an attempt to introduce the value of a design approach to this issue: How might we live with robots? I described how an ecological approach could help in exposing the problems related to (mal)adaptation, specifically robot form, function, and interaction. I then shifted the focus onto design to suggest that designers have the requisite knowledge of the home and its inhabitants to provide an alternative perspective on robot domestication. By necessity, this requires a rethinking of the subject and a relaxed approach to definition ${ }^{10}$.

The projects described above challenge expectations in different ways. The student brief that lasted over one month at the RCA introduced robots to many of the participants for the first time. This highlights the importance of the brief to the design community. We are rarely experts on one particular (technological) subject; the brief acts to condense the key points, factors, or problems suggesting areas to research further, define contexts and habitats of use, and suggest goals and outcomes for the project. The design brief has much in common with a scientific research question. The main difference is that the problems approached are less defined- design has the

\footnotetext{
${ }^{10}$ My attempt to define the robot can be read here: http://augerloizeau.tumblr.com/post/14318157271/arather-longwinded- definition-of-a-robot
} 
potential to identify research directions that are "orthogonal" to the original research aims and more closely related to everyday life. Student briefs in particular are written with the aim of encouraging as broad a range of possibilities as possible.

A confident designer will happily re-work the brief should the opportunity or necessity arise. For example, in Diego Trujillo's project, he discovered during the research phase that the physical complexity of the home raises huge engineering challenges for those designing robots to operate in it. The solution was to rework the brief and redesign the home. This was a four- week project, so the outputs were limited to imagery. It is easy to imagine the benefits of collaboration between Diego and a roboticist, examining the key problems of the home and designing compromises that could elicit a comfortable cohabitation.

A good brief also approaches the subject of purpose, but rather than defining it from the outset, the research can explore possible options. To refer again to Charles Eames (1972) definition of design - with robots the elements in need of arranging are clear and straightforward, a problem arises when we simply ask, "What is a domestic robot's purpose?" Emphasising focus on the strengths of the robotic elements, the student brief asked for new purposes. Neil Usher (2012), with his concept of Pareidolia, found original and though-provoking new roles for robots that also have a grounding in the increasing levels of automation in everyday life, which raised important ethical and social questions.

I also discussed speculative design. A key factor in the success of speculative design projects is careful crafting the fictional element. As such, fictional elements are consciously audience specific, e.g., Trujillo's (2011) With Robots is primarily orientated towards the robotics community due to his use of optical markers and the technical nature of the problems he addresses. James Chamber's (2010) ADG objects work across communities due to the familiarity of the products and the fictional construct behind them. Dunne and Raby's (2007) robots are more challenging. As physical objects they are not familiar in any sense, and the video (and supporting images) used to describe them are highly staged and theatrical. For me, the project is almost pushes the speculative element too far... until I read the supporting explanations. The designers craftily avoid the subject of function by distracting with the oddness of the objects and scenography, then focusing on interaction-a very emotional, empathetic, and human form of interaction based on real fears, hopes, and imagination. These interactions allow the viewer to reconnect with the fiction and understand anew the HRI. Feral Robotic Dogs is not speculative at all, nor is it a fiction, but it exemplifies a complete understanding and manipulation of a habitat (the mediascape), exploiting the robot's unique place in popular culture to raise and communicate social and political issues.

Many of these approaches were combined with the Carnivorous Domestic Entertainment Robots. While they were extremely successful at engaging a broad range of audiences, there were problems with the management of the project. After analysing the comments on blogs and websites, it became clear that the CDERs were suffering from familiar negative film depictions of robots. In this case, the similarities between 'The Matrix' (humanity is captured by a race of machines that live off their body heat) and the carnivorous behaviour of the robots led to inevitable comparisons. We used 'entertainment' in the title as a nod towards the familiar concept of entertainment robots but this became a negative focal point leading to accusations of animal cruelty. These issues exemplify the fine line of speculations as a serious investigation into robot domestication. Facile comments based on assumptions that robots will take over the world are frustrating to the professional designer as they deflect the discussion away from more valuable themes. In some cases, such as the Feral Robotic Dogs, the robot's reputation can be helpful in generating publicity, but more often than not, it is at best a distraction and at worst a powerful influence that can blinker the viewer towards more logical, valuable, and relevant issues or solutions. 
Auger, Living with Robots

\section{Conclusions}

Conflict and ill-feeling can commonly arise when an outsider expresses new or critical observations in an established field. It is helpful, of course, to understand where the commenter is coming from; what experience or qualifications validate their opinions? Why should they be taken seriously? Design, just like robotics, is a broad subject with many disparate fields, motivations, and methods. Also like ' robots', the term is in popular use and stereotypical ideas often dominate common perceptions - in design these might be influenced by home makeover television programmes and the rise of the celebrity designer. Certainly roboticists would be justified in being suspicious of suggestions coming from this form of designer, but as described above, other forms of design can provide a far more complex and valuable set of insights and skills. Coming back to Eames (1972) description of design, when the elements to be arranged exist as profound new technologies, "how they are arranged?" and "for what purpose?" become extremely important questions. Robots remain a fascinating technological subject due to the unique place they hold in both popular and research culture. While there has been much arrangement of robot related elements, purpose in domestic life remains very unclear. Stereotypical ideas continue to exert their influence, blinkering approaches from alternative possibilities; a design influence on HRI simply encourages more focus on the complex reality of everyday life, the idiosyncrasies of people, the role of trends, status symbols, aesthetics, and more. Ideas of adaptation and domestication, applied through design to robot related technologies, could provide new routes for robots to finally meet our expectations. One final point is that designers rarely work alone and the best projects emerge from genuine collaborations. In Design Interactions Research at the RCA we are beginning to develop relationships with several research institutions with the key aim of bringing design and science together

\section{Acknowledgements}

Thanks to the students, alumni and staff of Design Interactions, and the EPSRC, Intel and Microsoft for funding.

\section{References}

Ballard, J.G. (2006). The Complete Short Stories: Volume 1. Harper Perennial. London.

Baudrillard, J. (2005). The System of Objects. London: Verso.

Behnke, S. (2008). Humanoid Robots—From Fiction to Reality? Künstliche Intelligenz-KI 22(4), 5-9.

Berker, T. (2006). Domestication of Media and Technology. New York: Open University Press.

BLDGBLOG (2011, August 1). The New Robot Domesticity. Retrieved from http://bldgblog.blogspot.co.uk/2011/08/new-robot-domesticity.html

Bradbury, R. (2008). The Illustrated Man. London: Harper Voyager.

Breazeal, C. (1999). Proceedings of the Agents99 workshop on emotion-based agent architectures:

Robot in society: Friend or appliance? Seattle, WA. Retrieved from http://www.ai.mit.edu/projects/sociable/publications.html

Bristol Robotics Laboratory (BRL). (2013). EcoBot II. Bristol, England: University of Bristol. Retrieved from http://www.brl.ac.uk/researchthemes/bioenergyselfsustainable/ecobotii.aspx

Brooks, R. A. (1996). Proceedings of the First International Symposium on Humanoid Robots (HURO): Prospects for Human Level Intelligence for Humanoid Robots. Retrieved from http://people.csail.mit.edu/brooks/papers/prospects.pdf 
Auger, Living with Robots

Chambers, J. (2010). Artificial Defence Mechanisms. Retrieved from http://objects.jameschambers.co.uk

Dezeen (2011, August 12). With Robots by Diego Trujillo Pisanty. Retrieved from http://www.dezeen.com/2011/08/12/with-robots-by-diego-trujillo-pisanty/

Digard, J. P. (1990). L'Homme et Les Animaux Domestiques: Anthropologie d'une Passion. Paris: Fayard.

Dixon, D. (1981). After Man: A Zoology of the Future. New York: St. Martin's Press

Dobzhansky, T., Hecht, M. K., \& Steere, W. C. (1968). On some fundamental concepts of evolutionary biology. Evolutionary Biology, 2, 1-34. NewYork: Appleton-Century-Crofts.

Dunne, A., \& Raby, F. (2007). Critical Design FAQ. Retrieved from http://www.dunneandraby.co.uk/content/bydandr/13/0

Eames, C., \& R. (1972). Design $Q \& A$ [DVD]. United States: Pyramid Media. Available from http://www.pyramidmedia.com/homepage/search-by-title/humanities/films-of-charles-rayeames-4- detail.html

Elton, C. (1966). Animal Ecology. London: Methuen and Co.

Gates, B. (2007, January). A Robot in Every Home. Scientific American 296(1), 58-65.

Herzog, H. A., Bentley, R. A., \& Hahn, M. W. (2004). Proceedings of the Royal Society London B, Biology Letters: Random drift and large shifts in the popularity of dog breeds. London: Royal Society Publishing.

Mast, G., \& Cohen, M. (1985). Film Theory and Criticism. New York: Oxford University Press.

Material Beliefs. (2013). Retrieved from http://materialbeliefs.com

Odum, E. P. (1971). Fundamentals of Biology. Philadelphia, PA.: W. B. Saunders Company.

Pollan, M. (2002). The Botany of Desire. London: Bloomsbury.

Rybczynski, W. (1987). Home: A Short History of an Idea. New York: Penguin Books.

Schaut, S. (2006). Robots of Westinghouse 1924 - Today. Mansfield, OH: Mansfield Memorial Museum.

Shelley, M. (1992). Frankenstein. London: Penguin Classics.

Tharp, B., \& Tharp, S. (2012). Discursive Design. Retrieved from www.discursivedesign.com

Trujillo, D. (2011). With Robots. Retrieved from www.trujillodiego.com/work/withrobots.html

Usher, N. (2012). Design Interactions. Retrieved from www.di12.rca.ac.uk/projects/pareidolicrobot

Varsi, A. C., \& Smith, B. (1999). The Niche. Nous, 33(2), 198-222. Retrieved from http://ontology.buffalo.edu/smith/articles/niches.html

Wired (2011, August 3): Household items redesigned to help domestic robots. Retrieved from http://www.wired.co.uk/news/archive/2011-08/03/homes-adapted-for-robots

Wurtzel, J. (2001, September 11). Life with a robot dog. BBC News. Retrieved from http://news.bbc.co.uk/1/hi/in_depth/sci_tech/2001/artificial_intelligence/1536962.stm

Author's contact information: J. Auger, Royal College of Art, London, England. Email: james.auger@rca.ac.uk 